\title{
Application of Genetic Algorithm into Multicriteria Batch Manufacturing Scheduling
}

\author{
Aleš Slak1,* - Jože Tavčar² - Jože Duhovnik ${ }^{3}$ \\ ${ }^{1}$ Iskra ISD-Strugarstvo d.o.o., Slovenia \\ 2 Iskra Mehanizmi, Slovenia \\ ${ }^{3}$ University of Ljubljana, Faculty of Mechanical Engineering, Slovenia
}

Technical innovations in the area of manufacturing logistics are introduced partially and thus fail to realize their full potential. In order to optimise the efficiency of turning manufacturing processes, the production planning and scheduling, cutting tools and material flow process, manufacturing capacities have been analysed. All data from production operations, quantities and the, duration of operations are now kept in the ERP system. It provided the necessary condition for the establishment of a robust planning model, which includes stock control of material and cutting tools. An update was required for the whole lifecycle of products and means of work. The article presents information and an algorithm for a dynamic scheduling model, based on a genetic algorithm. The orders on the machines are scheduled on the basis of a genetic algorithm, according to the target function criteria. The algorithm provides a satisfactory, almost ideal solution, which is good enough for implementation in practice. With the GA the machine utilization increased, throughput time was reduced and costs and delivery delays improved. The presented model of GA also allows further optimisation of manufacturing plans and the machines layout.

(C2011 Journal of Mechanical Engineering. All rights reserved.

Keywords: genetic algorithm, multicriteria scheduling, batch production, target function

\section{INTRODUCTION}

In the traditional approach, planning and scheduling are two separate and successive operations. The production planning phase mostly includes the physical aspect of planning, where a product range, production quantities, machines, tools, material and accessories are selected. The emphasis in the second, scheduling phase, is on the time aspect. The plan is the basis for determining the sequence of operations across available machines in a way that provides maximum machine utilisation and timely manufacturing. Differences between planning and scheduling criteria often lead to conflict situations or even opposition between respective goals.

Master production schedule (MPS) and capacity requirement planning (CRP) in the environment of manufacturing resources planning (MRPII) are the most frequently applied traditional methods in practice. This system is characterised by a hierarchical approach from top to bottom. Goals and restrictions at the lower level are determined by the results at the higher level. Such a planning method rarely takes account of the scheduling problem. Separate treatment of planning and scheduling often results in plans having to be manually modified. This leads to significant rearrangement costs and supply delays. Nowadays, such planning does not provide efficient business operations as customers and the market require flexibility and quick response.

The solution for such problems is the integration of the planning and scheduling processes. The article presents a solution on a case study of planning and scheduling in the batch production. Presented is a planning model and its advantages, compared to the existing method of work. A genetic algorithm was used to optimise scheduling. The updated process planning improved the efficiency of production and reliability of supplies.

\section{LITERATURE REVIEW}

The change of planning was triggered by the requirement for flexibility and quick response to market and consumer needs. J. Errington [1] presented the advantages of Advanced Planning and Scheduling (APS), compared to traditional

*Corr. Author's Address: Iskra ISD-Strugarstvo d.o.o., Savska loka 4, SI-4000 Kranj, Slovenia, ales.slak@iskra-isd.si 
methods. Here, individual steps of the traditional approach are merged in a way that allows automatic transition. Tasič et al. [2] presented advanced scheduling methods, such as priority rules, useful also for sophisticated systems.

Computer Aided Process Planning (CAPP) has been recognised to play a key role in Computer Integrated Manufacturing (CIM) [3]. Traditionally, nearly all computer aided process planning (CAPP) supposes that manufacturing is of secondary importance and that the workshop has unlimited resources. This triggers unrealistic plans that are unworkable in the manufacturing process.

Planning and scheduling functions often have opposing goals, which makes their separate treatment less efficient. The other deficiency of separate treatment is not taking account of the dynamic manufacturing environment. The time delay between process planning and the actual beginning of the plan can cause the plan to become unworkable. Fixed plans lead to bottleneck situations. Research has shown that as many as 20 to $30 \%$ of all plans have to be modified in order to be adjusted to the dynamic manufacturing environment.

Integration between the planning and scheduling process is, therefore, vital as this is the only way to create more realistic plans and schedules. Only this will result in real CIM [4]. The integration creates a single space for solutions and provides the basis for efficient integrated solutions that are in the interests of both, planning and scheduling [5]. This contributes to an improved efficiency of manufacturing resources, shorter throughput times, scheduling times and shorter delays. The integration of planning and scheduling is much more complex and more difficult to achieve in practice. Kumar et al. [6], suggested introducing on-line scheduling in a CAPP system where real time status of the shop floor is crucial and dynamic feedback is required for scheduling.

Larsen [7] and Alting [3] arranged different approaches to integrated process planning into three types; The concept of non-linear process planning (NLPP) or flexible process planning, closed loop process planning (CLPP) and distributed process planning (DPP).
The CLPP approach involves generating plans by means of a dynamic feedback from the shop floor. It is better than NLPP since plans are generated with a view to realistic conditions in the manufacturing environment. With this method, the realistic conditions are vital and the feedback is important for the scheduling process.

DPP performs process planning simultaneously with the scheduling of manufacturing. Process planning is divided into two phases. The first phase is the initial phase where product requirements are analysed according to its shape, tools, machines etc. When all the requirements are satisfied, the second phase or final planning begins. During this phase, the required manufacturing resources and the available resources are matched. The flexibility of this approach increases if the required resources are given as alternatives. Examples of such an approach are Wang and Shen [8] and the IPPM system by Zhang [9], followed by IPPS by Huang et al. [4].

Matching individual planning models has shown that DPP is the best approach. However, it still requires high performance hardware and software. NLPP involves alternative plans, which allows better scheduling flexibility. Such a method can be introduced in enterprises without the need for their reorganisation, compared to DPP and CLPP that would require reorganisation of the planning and scheduling departments. This is due to CLPP and DPP requiring the merging of different separate processes within an enterprise.

Several researchers merged individual approaches in order to remove the deficiencies and come up with optimum plans. Gao et al. [10] presented an integrated process planning and scheduling model, based on taking the advantages of NLPP (alternative plans) and DPP (hierarchical approach) models. Their model is based on the principles of concurrent engineering, where computer-aided planning and scheduling are performed simultaneously.

The concept of non-linear process planning is typical of integrated process planning and scheduling (IPPS). Usher and Fernandes [11] presented the PARIS system, which is designed to support dynamic process planning. It consists of two phases; static and dynamic. Each phase is characterized by objectives that should be met. 
Kumar et al. [12] proposed the integration of process planning and scheduling activities through two controlling modules - the process plan generator and scheduler. Jain et al. [13] and Razfar et al. [14] propose a similar way, by dividing the problem into two modules.

Nowadays, modern manufacturing systems should be adapted to the changes on the market. They all have the same objective - the lowest possible manufacturing costs. On the other hand, they wish to meet quality and timely delivery requirements of customers. Starbek et al. [15] developed a method which enables the delivery time of a new product on the basis of actual throughput times of previous products. The suggested procedure also allows changes of the calculated delivery time with regard to confidence and risk level. Kopač et al. [16] presented modern techniques together with methods for the reduction of throughput times and improved quality.

The importance of artificial intelligence has grown due to an increased complexity of planning problems. Methods, based on a genetic algorithm, for example, are very efficient for difficult problems. They do not always yield the best absolute solution but they find an approximation, good enough for practice. Balič et al. [17] used genetic algorithms in order to arrange machines and apparatus in a flexible processing system. They used variable transferable costs as their target function. Yan and Zhang [18] developed a uniform planning and scheduling optimisation model for the management of a three-tier manufacturing system. In order to solve the problem, they opted for a heuristic approach, based on genetic algorithms. They developed an algorithm where they determined the optimum size of a batch. Park and Choi [19] suggested the use of genetic algorithms (GA). The target function was the shortest production time of all products, while taking account of alternative machines and alternative sequence of operations. Using genetic algorithms Kimms [20] solved a mixed integer program formulation which he had developed for multi-level, multi-machine scheduling. Zhang and Yan [21] defined the planning and scheduling problem as a nonlinear mixed integer program model. For the purpose of simultaneous optimisation of production planning and scheduling, they presented an improved hybrid genetic algorithm (HGA). To improve the results, they also used heuristic rules, i.e. the shortest processing time (SPT) and the longest processing time (LPT). Lee and Kim [22] suggested simulation with a genetic algorithm, linked with a simulation module that calculates the success rate of planning, based on combinations between process plans. Total production time and delivery date were used as target functions. Gao et al. [10] suggest the use of a modified genetic algorithm where each function (process planning and scheduling) was given a different chromosome representation. Minimum throughput time of all products was used as the target function. For the integrated model a mathematical model, solved with genetic algorithms was introduced [23]. Lestan et al. [24] developed a simple genetic algorithm for a job-shop problem. Makespan as a target function was used and the solution was found without the help of heuristic rules.

The article describes a new approach with GA in the batch production. Separate functions, production planning and scheduling are put together in one system. A planning model which comprehensively covers production planning has been developed. Constructing the model has shown that planning should also include material and tool purchases as well as product sales. This model has served as a basis of determining a satisfactory plan with genetic algorithms. Several target functions and criteria are present in the optimisation procedure. This has improved productivity, utilisation of machines and delivery times. Presented are also experimental results and a comparison with other authors is given.

\section{PROBLEM DESCRIPTION: PLANNING AND SCHEDULING IN BATCH PRODUCTION}

Planning and scheduling of products in the production of turned parts are complex problems. An $n$ number of products should be scheduled across an $m$ number of machines in the way that they will be manufactured and delivered to the customer on time. Each product has at least one alternative plan that includes several operations and is also the end product. Each operation is performed on a single machine. Currently, plans are made manually and everything depends on 
a single person who relies on their experiences. Some products are subjected to planning according to a MRP system. It is a well-known fact that such a system does not always lead to workable plans, which makes it is almost useless in a dynamic environment. For this reason planners extend the product's throughput time and thus deliberately extend delivery times. In turn, this creates longer queues, less flow through production, less effective utilisation of machines and higher production costs. Current planning does not provide any feedback on the situation of manufacturing resources and response to any change on the shop floor (machine failure, urgent order) is poor. The number of items for a single operation is not known and the whole potential of the information system is not exploited. This results in high consumption of time to coordinate plans and scheduling causes conflict situations.

Since process planning and scheduling are closely related functions, their integration in such an environment is vital for the creation of the best plan.

\section{INTEGRATION OF TWO MAIN FUNCTIONS: PRODUCTION PLANNING AND SCHEDULING}

The basis for our work was the existing ERP (Enterprise Resource Planning) information system, which represents the backbone of our dynamic planning system. Fig. 1 shows the overall procedure for the integration of the production planning and scheduling functions. It is basically divided into two modules - the first module or production planning module, where all alternative plans for each product are determined, and the second module or scheduling module with the genetic algorithms approach. In the first module, the static or pre-planning phase is performed, with the emphasis on specifying various plans according to available resources and specifying production quantities and material needs. The second module involves the final planning phase, where target functions and realistic conditions in the manufacturing environment are considered. This means that the available resources are matched with the required ones. If the current capacity does not meet the requirements, an extra plan should be included in the process. In practice, this means that a product is being manufactured simultaneously on two machines.

First, from the CAPP system all orders are collected, followed by making a rough plan by means of gathering the information on the available capacity of regular orders that are always manufactured on a single machine. For other orders, alternative plans are prepared according to other available resources. This is followed by specifying material needs and capacity for all production quantities.

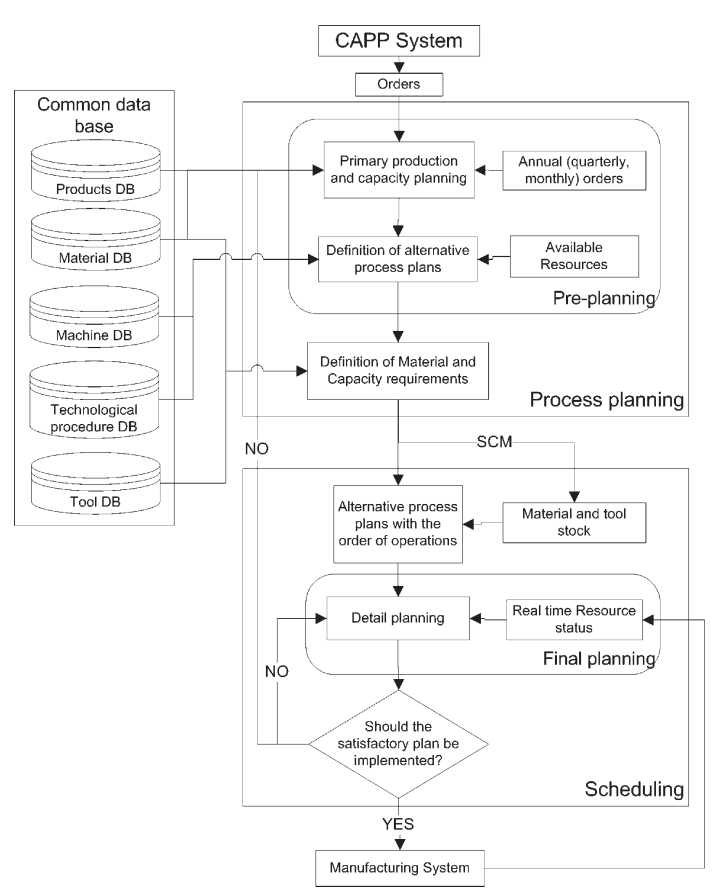

Fig. 1. Integrated model with production planning and scheduling function

When alternative plans, manufacturing procedure (sequence of operations), required quantities of material and tools are available, a scheduling module for which these are the input data begins. In this module the final planning phase is performed and its key role is to schedule all product operations across machines in a way that meets the scheduling criteria. Detailed planning of the manufacturing plan is subject to timely delivery of materials and tools by suppliers. Specifying the optimum plan, the target functions are the minimum throughput time of all products and minimum total costs. At the same 
time, another aim is to achieve the most effective utilisation of machines, reduction of set-up times for the first operation and to minimise order delays.

Once a satisfactory schedule has been completed, it is considered as a working frame. If urgent orders arrive after the schedule has been completed, certain tasks are given higher priority. If an order has been cancelled or there is an equipment failure, a new schedule should be created. Due to the above-mentioned reasons it again functions as a frame. If there are no modifications, the optimum schedule should take place on the shop floor.

The following assumptions have been specified for the solution of such a problem:

- Only one product can be produced on one machine at the same time;

- Each product can be machined independently from other products;

- Each product has one to three alternative plans (different CNC machines);

- The sequence of operations is predefined for each product in the alternative plan.

\subsection{Advantages and Disadvantages of the Proposed Method}

The integration of production planning and scheduling has led to the shift from manual scheduling to automated, computer-aided planning. Defining a detailed time when the manufacturing process of an order will start and when it will end, including delivery time, is the biggest advantage. Each operation on a product has a specified start time and end time. For example, it is specified when and how many products should be ready for galvanic coating. A planner is now able to check in any given moment which products are being produced on which machines and how many of them are on each operation. Such a planning method gives a planner a more supervisory role as they can follow via the information system what goes on on the shop floor and is informed whether an order is behind or ahead of schedule.

Manual methods include a lot of verbal communication with the shop floor, physical checks of machines on the progress of the work, which is now no longer necessary. The automated planning and scheduling system also allows control over finished products, material and tools. Planning requires consistency in the monitoring of products on each operation throughout the manufacturing process. This information allows an accurate prediction of how many products can be finished in a short period of time. This is important in the case of increased demand for a product by a customer. The most important thing for managing a dynamic manufacturing environment is a quick and efficient response to changes, such as machine failure, maintenance work, and urgent orders. This means that if the machine breaks down, then new borders are put into the planning system. The products that have already been put on the machine get the status "in progress" and they cannot be withdrawn, but the products with the "plan" status can be rescheduled. This status is written in the ERP system. The same procedure applies to urgent orders. A new plan can be made any time, the response time for a new plan is 15 minutes, on average. Information about the finished operations from the production is an automatic update in the ERP system every 30 minutes.

Managing changes of materials and tools delivery dates by suppliers could be a drawback of production planning. If materials and tools are out of stock or they are not supplied on the planned date, the plan is unworkable and should be delayed by at least one day, which can trigger delays in the supply of end products.

\section{USER INTERFACE BETWEEN ERP SYSTEM AND SCHEDULE OPTIMISATION SOFTWARE}

A manufacturing information system is the backbone of the planning and managing of production, which is why the existing information system within the planning model has been complemented rather than replaced. All data are stored in the ERP information system. In order to calculate the near optimum plan and schedule, data are exported and optimisation of the plan with genetic algorithms is performed. The collected data are then returned to the information system. The whole system of data management is shown in Fig. 2. 
Data are exported from the information system with the Oracle Discoverer 4.1 application. The proposed algorithm is performed once a day or at a request into a purpose built software application (relational base MS Access, Visual Basic). Later, a transition to Oracle base and $\mathrm{C}++$ is planned. A genetic algorithm was used and proved very fast and with good conversion results. This local base is the groundwork for planning on the basis of the data from the basic information system. The optimisation procedure results in a detailed plan and schedule of products manufacturing. It serves as input information and enables the planner to generate manufacturing product tasks within the ERP system.

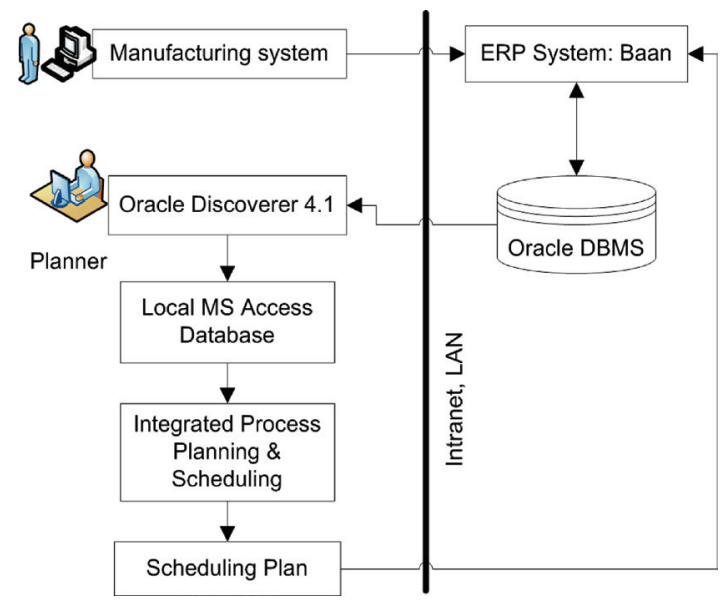

Fig. 2. Data flowchart

The Oracle Discoverer application allows access to the data base, located in the information system. Each ERP session has a table with data that are also visible in the session itself. Necessary information is specified in the Oracle Discoverer application. The application also allows data filtering, additional equations-based restrictions, similar data pooling etc. The selected data are exported into the local relational base that functions as the basis for planning and scheduling. The relational data base is created in MS Access which serves as the basis for the plan. Each field is written in the same way as in the table in the ERP (Baan) system. The same applies to tables names.

A purpose application has been created for the optimisation process. On the basis of the ERP information system it schedules the activities on the shop floor in real time. Genetic algorithms have proved to be an efficient method for product scheduling.

\section{GENETIC ALGORITHM-BASED APPROACH FOR PRODUCTION SCHEDULING}

Genetic algorithms (GA) are a method of evolutionary computation. Genetic algorithms are a random search technique, not requiring detailed knowledge about a problem that is being optimised.

Fig. 3 shows the application of the genetic algorithm procedure. At the beginning, all alternative plans and other relevant information for the calculation of a satisfactory plan are gathered. Other data include delivery dates, stock information, materials and tools supply. In the next step, a population is randomly generated. It consists of a large number of different possible plans. On the basis of target functions and restrictions, each chromosome of the initial population is evaluated. The evaluation process is then carried out, with better and better solutions being sought on the basis of selection, reproduction, crossover and mutation until the required condition is reached. The condition in our case was a maximum number of generations.

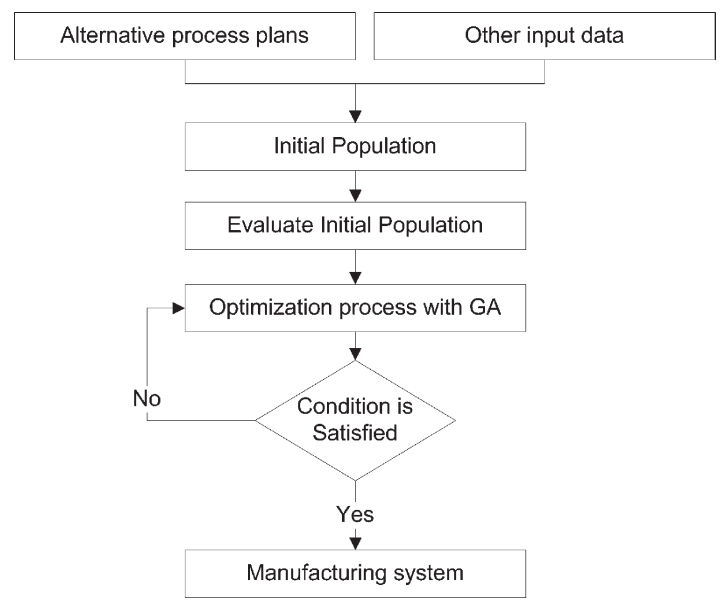

Fig. 3. Course of the application of the genetic algorithm

Genetic algorithms represent solutions of problems in structures, called chromosomes. The collection of chromosomes is called a population 
and specific chromosomes in the population are individuals. A population at any given time is called a generation. The goal of genetic algorithms is to create new generations. Although the population can change from generation to generation, the size of the population and the structure of chromosomes remain the same. They operate with characters, representing parameters. Proper specification of parameters or chromosome syntax is an important step. It has an effect on subsequent work with genetic algorithms and on the share of workable solutions in the search area in terms of a large number of plans and restrictions. The literature has so far presented the chromosome in a number of ways [25]. Below are presented the chromosome, the evolutionary function with restrictions and genetic operators. The chromosome has been adapted to the needs of the production of turned parts.

\subsection{Chromosome Representation}

A job-based representation of a chromosome has been chosen to represent the chromosome of the given problem. The manufacturing type in the company is by orders. One product is represented by one gene in the chromosome. The gene is represented by two pieces of information, with the first one being the number of the alternative plan according to which the product will be manufactured while the other one specifies whether tools presetting will take place (number 1 ) or not (number 0 ). The gene can be extended to other characteristics. The chromosome is shown in Fig. 4. The chromosome is made up of a group of genes. In our case this is the schedule of all the products to be manufactured. This means that the chromosome represents a permutation of tasks. Representation of the chromosome by products belongs to direct approaches, where the solution is built in the chromosome. Genetic algorithms are used for the creation of the chromosomes whose objective is to find a better schedule. First, operations of the first product in the chromosome are scheduled across machines. They are followed by the second product's operations and so on to the last one in the chromosome.

When the target function of the chromosome is calculated, it has to be decoded back to the solution of the problem, which means the schedule of products. During the encoding it is of the utmost importance to keep the subsequent solution of each chromosome decoded within the possible space of a given problem. This feature is called feasibility. When the generated chromosome cannot be decoded into a solution, correcting techniques are applied. They change an illegal chromosome into a legal one. This feature is called illegality.

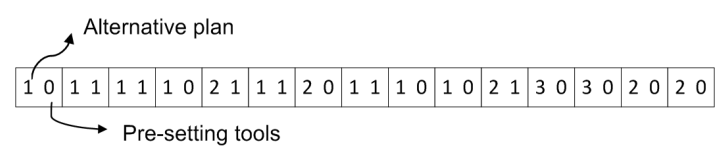

Fig. 4. Chromosome

The relational database contains information on products that is used for the purpose of order scheduling. The list of genes or the chromosome represents one possible schedule on the shop floor. Using GA, a satisfactory schedule, as close to the optimum as possible, should be found. The GA principle is similar to natural evolution. Only the strongest individuals survive, creating a new and more advanced population of descendants by means of gene mutations and their crossover.

\subsection{Evaluation Functions}

The shortest makespan and minimum manufacturing costs were set as target functions and manufacturing restrictions and customers' requirements were considered. Delivery time is the most important customer requirement. Other restrictions and criteria are described later on. Special emphasis is on the products where one of the operations is performed at an outsourcer. Together with the making itself, the manufacturing time also involves machine set-up and finishing times. Total costs consist of manufacturing costs, labour costs and depreciation costs.

Mathematical model symbols:

$N \quad$ Number of orders or work orders,

A Number of items on the bill of material,

$M \quad$ Number of machines on the shop floor,

$P_{i} \quad$ Number of alternative plans for product $i$,

$G_{i l} \quad$ Number of operations for product' $i$ plan 1, 
$o_{i l k} \quad k$-operation for product's $i$ plan $l$,

$Q_{o, i} \quad$ Ordered quantity of product $i$,

$Q_{p, i}$ Quantity of product's $i$ workpieces, overlapping with the next operation,

$t_{p o, i l k j}$ Time of operation's $o_{i l k}$ overlap on machine j,

$t_{t, i l k j}$ Technological time for the production of one product $i$ for operation $o_{i l k}$ on machine $j$,

$t_{w, i l k j}$ Processing time for operation $o_{i l k}$ on machine $j$,

$t_{\text {op, } i l k j}$ Time of the performance of operation $o_{i l k}$ on machine $j$

$t_{p z, i l k j}$ Set-up and finishing times of machine $j$ for operation $o_{i l k}$

$t_{e s, i l k j}$ The earliest beginning of operation $o_{i l k}$ on machine $j$

$t_{e f, i l k j}$ The earliest end of operation $o_{i l k}$ on machine $j\left(d_{f, i l k j}\right)$

$t_{p, i} \quad$ Product's $i$ throughput time

$t_{p, j} \quad$ Throughput time for all operations, performed on machine $j$, i.e. total time when a machine is engaged in the performance of all planned operations

$t_{s, i l k j} \quad$ Set-up time of machine $j$ for operation $o_{i l k}$

$t_{m o, i l k j}$ Time of interoperational hold-up for operation $o_{i l k}$ on machine $j$

$w_{i} \quad$ Product $i$ priority

$d_{d, i} \quad$ Scheduled delivery date of product $i$ to the customer

$t_{p, \max }$ Maximum time on machine among all machines

$c_{s s c, i}$ Manufacturing costs for one piece of product $i$ (all operations, materials, tools)

$c_{d} \quad$ Labour costs

$c_{a, j} \quad$ Depreciation cost for machine $j$

$c_{s, i l k j} \quad$ Cost of machine $j$ for operation $\mathrm{o}_{\text {ilk }}$

$c_{p z, i l k j}$ Cost of operation's $o_{i l k}$ set-up and finishing time on machine $j$

$c_{w, i} \quad$ Total cost for processing all operations for product $i$

$c_{p, i} \quad$ Total costs for product $i$

$C \quad$ Total costs for all products

$m n u_{j} \quad$ Non-utilisation of machine $j$

$M U$ Maximum utilisation of all machines

$D \quad$ Large positive integer

$Z_{i} \quad$ Delivery delay of product $i$ (in the number of days)

cwf Combined weighted function

$\lambda \quad$ Weight of delay $\delta \quad$ Costs of 1 day delay of the delivery date

$\alpha_{i i^{\prime} j}=\left\{\begin{array}{c}1 ; \text { product } i \text { appears before } \\ \text { product } i^{\prime} \text { on machine } j \\ 0 ; \text { product } i \text { DOES NOT appear } \\ \text { before product } i^{\prime} \text { on machine } j\end{array}\right.$

$\beta_{i l}= \begin{cases}1 ; & \text { alternative plan for product } i \text { IS selected } \\ 0 ; & \text { alternative plan for product } i \text { IS NOT selected }\end{cases}$

$\gamma_{i l k}=\left\{\begin{array}{l}1 ; \text { operation is performed simultaneously } \\ 0 ; \text { operation is performed sequentially }\end{array}\right.$

Target functions:

a) Minimum throughput time of all tasks and operations on a single machine:

$$
\begin{aligned}
& \operatorname{Min} t_{p, \max }= \operatorname{Max}\left\{t_{p, 1}, t_{p, 2}, \ldots, t_{p, M}\right\}, \\
& j=1, \ldots, M, \\
& t_{p, j}=\sum_{i=1}^{N}\left(\sum_{l=0}^{P_{i}} \sum_{k=1}^{G_{i l}}\left(t_{o p, i l k j} \cdot \beta_{i l}\right)\right) .
\end{aligned}
$$

Time of the performance of operation:

$$
t_{o p, i l k j}=t_{p z, i l k j}+t_{w, i l k j}=t_{p z, i l k j}+t_{t, i l k j} \cdot Q_{o, i} .
$$

Overlap time:

$$
t_{p o, i l k j}=t_{t, i l k j} \cdot Q_{p, i} .
$$

b) Timely delivery with minimum delays:

$$
\begin{gathered}
\operatorname{Min} Z_{\max }=\operatorname{Max}\left\{Z_{1}, Z_{2}, \ldots, Z_{N}\right\}, \\
i=1, \ldots, N, \\
Z_{i}=\left\{\begin{array}{rr}
0 & ; \text { if } d_{d, i}>d_{f, i l G_{i l}} \\
d_{f, i l G_{i l}}-d_{d, i} & ; \text { otherwise }
\end{array}\right. \\
d_{f, i l G_{i l}}=t_{e f, i l G_{i l} j} .
\end{gathered}
$$

c) Minimum total manufacturing costs for all products:

$$
\begin{gathered}
C=\operatorname{Min} \sum_{i=1}^{N} c_{p, i}, \\
c_{p, i}=\sum_{l=0}^{P_{i}} \sum_{k=1}^{G_{i l}} \sum_{j=1}^{M}\left(\left(c_{p z, i l k j}+c_{s, i l k j}\right) \cdot \beta_{i l}\right)+c_{w, i} .
\end{gathered}
$$

Processing costs:

$$
c_{w, i}=c_{s s c, i} \cdot Q_{o, i} ; i=1, \ldots, N .
$$


Machine costs:

$$
c_{s, i l l j}=t_{o p, i l l j} \cdot c_{a, j} \cdot
$$

Set-up and finishing time costs:

$$
c_{p z, i l k j}=t_{p z, i l l j} \cdot c_{d} .
$$

d) Combined weighted function:

$$
\begin{aligned}
& c w f=\sum_{i=1}^{N}\left(c_{p, i}+c_{z, i}\right), \\
& c_{z, i}=\left(\lambda^{\wedge} Z_{i}\right) \cdot Z_{i} \cdot \delta .
\end{aligned}
$$

e) Maximum utilisation of all machines:

$$
\begin{gathered}
M U=\left(\frac{1}{\min \sum_{j=1}^{M} m n u_{j}}\right), \\
m n u_{j}=\left(1-\frac{\sum_{i=1}^{N} t_{w, i l k j}}{t_{\max , j}}\right) ; j=1, \ldots, M .
\end{gathered}
$$

All restrictions have to be considered for an optimum manufacturing schedule of turned parts. They are listed above. Below, they are presented in a mathematical form.

\section{Restrictions:}

a) Only one product can be processed on each machine at the same time:

$$
\begin{gathered}
\text { If } d_{d, i}<d_{d, i^{\prime}} \text { then } \\
t_{p, i l^{\prime} k^{\prime} j}-t_{p, i l l j}+D \cdot\left(1-\alpha_{i i^{\prime} j}\right) \geq t_{w, i T^{\prime} k^{\prime} j} .
\end{gathered}
$$

b) Sequence of operations is predefined for each product in the alternative plan:

$$
\begin{gathered}
t_{e s, i l k j}+t_{w, i l l j j}+t_{p z, i l(k+1) j^{\prime}} \leq t_{e s, i l(k+1) j^{\prime}} \\
i=1, \ldots, N ; l=0, \ldots, P ; k=1, \ldots G_{i l} ; \\
j, j^{\prime}=1, \ldots, M .
\end{gathered}
$$

c) Only one alternative plan can be selected for one product.

Assumption:

$$
\begin{gathered}
w_{i l}>w_{i(l+1)} \\
\sum_{l=0}^{P_{i}} \beta_{i l}=1 \quad \forall i \in[1, N] .
\end{gathered}
$$

d) Operation is performed simultaneously or sequentially.

Product's throughput times change because operation can be performed simultaneously or sequentially.

Throughput time for product $i$ where operations are performed sequentially:

$t_{p, i}=t_{e f, i l G_{i l j} j}-t_{e s, i l 1 j}=\sum_{k=1}^{G_{i l}}\left(t_{o p, i l l k j}+t_{m o, i l h j}\right)$.

Throughput time for product $i$ where operations are performed simultaneously:

$$
\begin{gathered}
t_{p, i}=\sum_{k=1}^{G_{i l}-1}\left(t_{p z, i l k j}+t_{p o, i l l k j}+t_{m o, i l l k j}\right)+t_{o p, i l G_{l} j}, \\
t_{m o, i l k j}=t_{e s, i l(k+1) j^{\prime \prime}}-t_{e f, i l k j} .
\end{gathered}
$$

e) Throughput times for each operation and product costs have to equal or exceed 0 :

$$
\begin{gathered}
t_{p, i l l j} \geq 0 ; c_{p, i} \geq 0, \\
i=1, \ldots, N ; l=0, \ldots, P_{i} ; k=1, \ldots G_{i l} ; j=1, \ldots, M .
\end{gathered}
$$

Target functions equations are written from Eqs. (1) to (5). Taking account of all the objectives can be termed a multi-objective problem. The most important objectives to achieve are minimum throughput time Eq. (1), timely delivery Eq. (2) and minimum total costs Eq. (3). Combined weighted function Eq. (4) is composed of total costs and delays. It is necessary to achieve the highest possible efficiency of machines Eq. (5), which reduces idle time on a machine.

Restrictions that appear in the algorithm are written from Eqs. (6) to (10). Eq. (6) determines that a machine can produce only one product at a time. The sequence of operations for two different products on the same machine depends on the delivery date. It applies to all operations for all products. Eq. (7) determines the sequence of operations to be fixed for each product. It further increases the complexity of the problem. Only one alternative plan can be used for each product, which is shown in Eq. (8). The first alternative technological process is used as the initial plan. Choosing only one possible plan automatically means that only one machine is designated for the performance of a single operation because the machine is hidden in the plan. Eqs. (9) and (10) 
determine a product's throughput time according to the way of operations performance. The algorithm also takes account of the fact that some operations take place consecutively and others simultaneously. Eq. (11) determines throughput time of each operation and all product costs should equal or exceed 0 .

\subsection{Genetic Operators}

\subsubsection{Selection}

Tournament-type selection was used. For this selection type, a certain number of chromosomes is selected, which then take part in the tournament. Two individuals are matched and the chromosome with the best value is selected. If the number of chromosomes to be matched increases in an algorithm, the pressure on the selection increases. Inferior chromosomes are not selected and thus do not take part in the creation of the next generation while at the same time good individuals also do not dominate the reproduction process.

\subsubsection{Crossover}

Two-point crossover was chosen as the crossover operator. Selected from the population are two parents who form two offspring. Two random points are selected in the chromosome, as shown in Fig. 5. The material between both points is exchanged between the parents. This always creates feasible solutions. The crossover operator is subjected to the probability that determines the use of the crossover chromosome.

\subsubsection{Mutation}

A mutation is about introducing new genetic material in the existing chromosome. It introduces variety in the population and broadens the search area. A mutation as well as crossover is subjected to some probability. For the existing problem, the uniform mutation was selected. This mutation is about each gene in a chromosome being attributed a random number, which is then matched with the probability of mutation. If the random number is smaller, the gene is subjected to a mutation. This is shown in Fig. 6 . Genetic operators were selected on the basis of a systematic comparison between the results of optimising and the necessary calculating time.

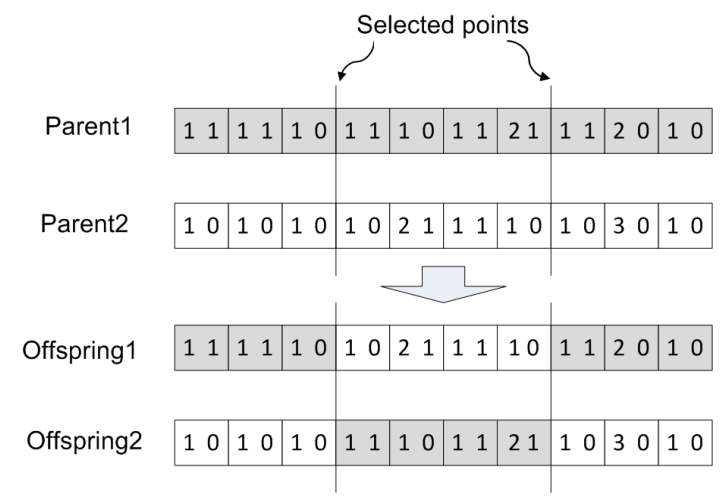

Fig. 5. Crossover operator

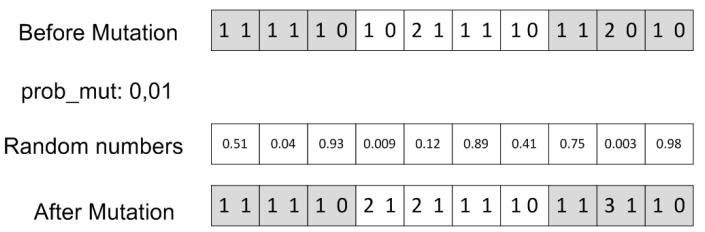

Fig. 6. Mutation

\section{EXPERIMENTAL RESULTS}

During the development of the genetic algorithm, several set-ups and approaches were systematically tested. Tests showed that with roughly 1000 evaluations it is possible to find a satisfactory solution for a plan. The size of the population was limited to 60 . A larger population extends the calculation time while there are no significant savings with the population sizes of 80 and 120 (Fig. 7).

The optimum selection was determined after comparing selections without the use of crossover and mutation operators. The roulette and tournament selections proved to be the best.

Two-point crossover with one-point mutation quickly converges towards a good solution but it also calms down quickly and is unable to look further for better solutions. A random mutation is looking for solutions to a larger extent and the convergence of the population towards better solutions is slower but the final solution is very good. For these reasons, two-point crossover with random uniform mutation is used 
in the final version. The crossover probability is set at 0.9 and the mutation probability at 0.01 .

For the purpose of determining the optimum solution for the production of a product or a product range, several alternative plans were used for each product. These plans are entered in the information system and their numbers of operations and designated machines for each operation are already specified. Thirty products were scheduled onto eighteen $\mathrm{CNC}$ machines in the case study. There are thirty machines and ninety-five operations all together. There can be up to four operations on a particular product and up to three alternative plans. Planned time in hours and machines for particular operations are shown in Table 1. In the case of alternative plans additional machines are specified in the same way as with products $\mathrm{J} 2, \mathrm{~J} 4$ and $\mathrm{J} 5$. In parenthesis, the machine is marked with $\mathrm{M}$ and next to it is the number of the machine.

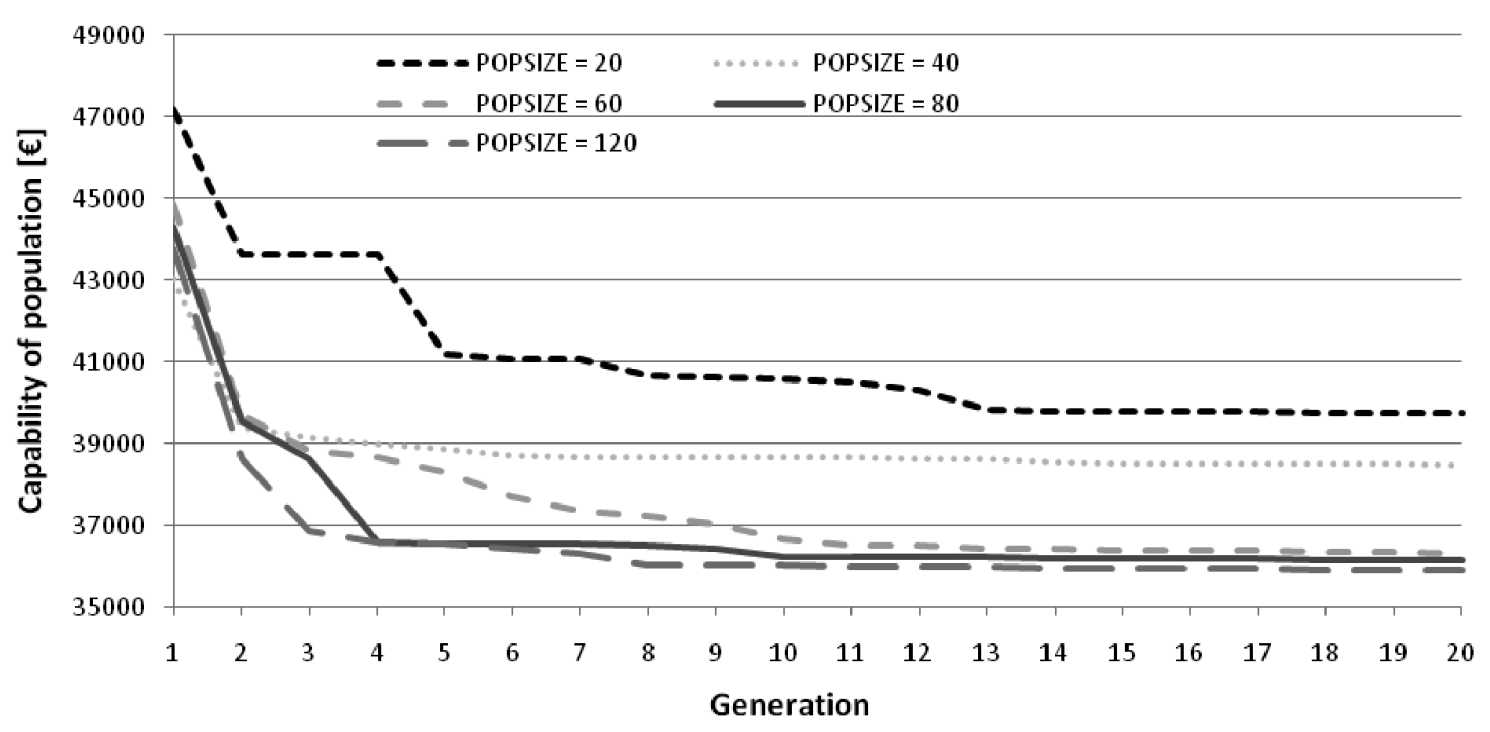

Fig. 7. Influence by size of population on convergence

Table 1. Processing time of all operations for a job with alternative plans

\begin{tabular}{|c|c|c|c|c|c|c|}
\hline \multirow{2}{*}{ Jobs } & \multicolumn{5}{|c|}{ Processing time } \\
\cline { 2 - 5 } & \multicolumn{3}{|c|}{ Operation 1 } & \multirow{2}{*}{ Operation 2 } & Operation 3 & \multirow{2}{*}{ Operation 4 } \\
\cline { 2 - 6 } & Plan 1 & Plan 2 & Plan 3 & & & \\
\hline J1 & $30.3(\mathrm{M} 13)$ & $/$ & $/$ & $0.8(\mathrm{M} 19)$ & $2.8(\mathrm{M} 27)$ & \\
\hline J2 & $35.1(\mathrm{M} 10)$ & $33.6(\mathrm{M} 8)$ & $33.6(\mathrm{M} 15)$ & $1.21(\mathrm{M} 19)$ & $1.04(\mathrm{M} 22)$ & $17.42(\mathrm{M} 26)$ \\
\hline J3 & $92.1(\mathrm{M} 13)$ & $/$ & $/$ & $1.3(\mathrm{M} 19)$ & $11.1(\mathrm{M} 27)$ & \\
\hline J4 & $10.8(\mathrm{M} 10)$ & $8.9(\mathrm{M} 12)$ & $/$ & $0.3(\mathrm{M} 19)$ & $0.3(\mathrm{M} 27)$ & \\
\hline J5 & $9.6(\mathrm{M} 10)$ & $8.7(\mathrm{M} 12)$ & $/$ & $0.3(\mathrm{M} 19)$ & $0.4(\mathrm{M} 27)$ & \\
\hline
\end{tabular}

Table 2. Results from the initial plan

\begin{tabular}{|l|c|c|c|c|c|c|}
\hline & $\begin{array}{c}\text { Total costs } \\
{[€]}\end{array}$ & $\begin{array}{c}\text { Throughput } \\
\text { time }[\mathrm{h}]\end{array}$ & Makespan [h] & $\begin{array}{c}\text { Sum of delays } \\
{[\text { day] }}\end{array}$ & $\begin{array}{c}\text { Utilization of } \\
\text { all machines } \\
{[\%]}\end{array}$ & $\begin{array}{c}\text { Combined } \\
\text { weighted } \\
\text { function } \\
{[\text { EUR] }}\end{array}$ \\
\hline $\begin{array}{l}\text { Initial } \\
\text { plan }\end{array}$ & 146269.6 & 4386.27 & 1257.58 & 83 & 23 & 452567.5 \\
\hline
\end{tabular}


For each target function an almost optimum solution was found with genetic algorithms. Solutions are good enough - satisfactory for production scheduling. Better solutions do exist but a minor difference does not make up for additional calculation time. The objective is to find the near optimum or satisfactory manufacturing plan out of the alternative plans in order to achieve good result of the fitness function.
The results of different target functions are summarized in Table 3. The size of the population was set to sixty and the number of generations to fifty. Calculation time on a middle class personal computer was 280 seconds for each target function from Table 3. The almost optimum solutions for particular target functions are highlighted. Other values in the same line are given for a comparison between different target functions. Each target function achieves the best result in the column

Table 3. Comparison between the values of target functions

\begin{tabular}{|l|c|c|c|c|c|c|}
\hline \multicolumn{1}{|c|}{ Target function } & $\begin{array}{c}\text { Total } \\
\text { costs } \\
{[€]}\end{array}$ & $\begin{array}{c}\text { Throughput } \\
\text { time [h] }\end{array}$ & $\begin{array}{c}\text { Makespan } \\
{[\mathrm{h}]}\end{array}$ & $\begin{array}{c}\text { Sum of } \\
\text { delays } \\
{[\text { day }]}\end{array}$ & $\begin{array}{c}\text { Utilization } \\
\text { of all } \\
\text { machines } \\
{[\%]}\end{array}$ & $\begin{array}{c}\text { Combined } \\
\text { weighted } \\
\text { function } \\
{[€]}\end{array}$ \\
\hline Total costs [€] & 116849.2 & 3565.60 & 421.55 & 29 & 51 & 161489.5 \\
\hline Throughput time [h] & 125131.9 & 3533.68 & 461.08 & 36 & 49 & 193800.8 \\
\hline Makespan [h] & 126840.1 & 3753.66 & 421.55 & 33 & 52 & 180927.5 \\
\hline Sum of delays [day] & 138955.9 & 4001.91 & 443.98 & 6 & 53 & 146468.9 \\
\hline Utilization of all machines [\%] & 153241.1 & 4139.53 & 443.98 & 48 & 58 & 259471.8 \\
\hline $\begin{array}{l}\text { Combined weighted function } \\
{[€]}\end{array}$ & 124658.7 & 3816.34 & 452.98 & 7 & 51 & 134035.1 \\
\hline
\end{tabular}

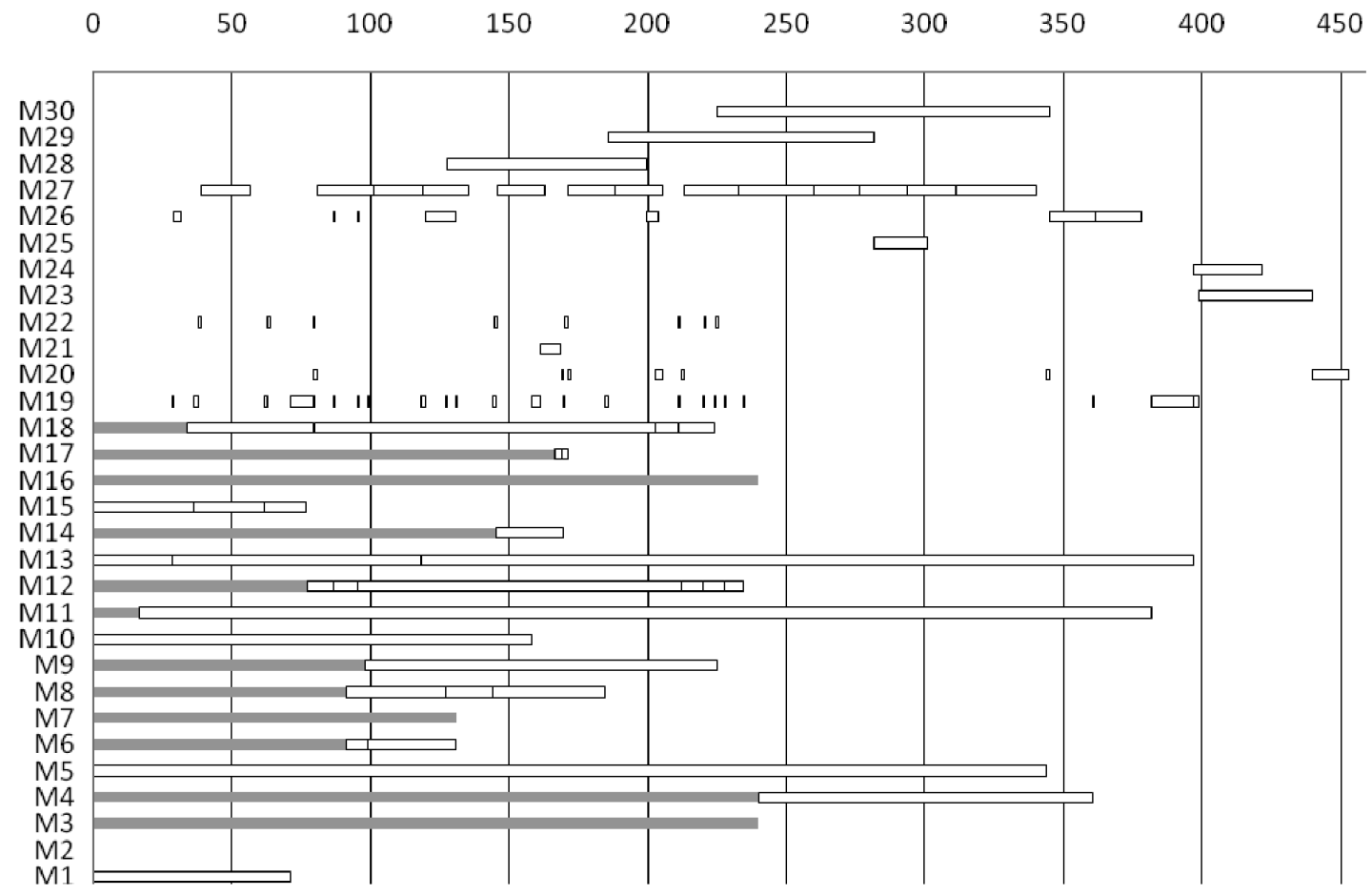

Fig. 8. Gantt chart for the operations from the scheduling problem 
- it matches expectations. Special attention was paid to delivering products on due dates and to control costs at the same time. We have set up a Combined weighted function model that considers both criteria: due date and costs. The comparison between the first and the second target function reveals that the results are very similar. Due to bigger makespan, the Throughput time function yields more delays and higher additional costs. In that case products are not well scheduled on the machines.

According to the minimum delays criteria the fourth target function is the best choice. In this case, products extend the throughput time and increase total costs although combined costs are at an acceptable level. The delays are only 6 days. The last of the target functions is a combined weighted function. It represents a compromise between total costs and delays. The value of this target function from Table 3 is not optimal, but it is a good solution acceptable to be used in practice.

Attention was also paid to the busiest machines on the shop floor and utilization of the machines. The maximum utilization target function, where the result is $58 \%$, the order of the products on the machines causes the longest delay. This is probably due to the order of the products on the machines. All products produced together result in very good efficiency, but some products will be delayed because of this.

Other researchers report that 1200 calculations with the genetic algorithm represent a good enough solution that could be put into practice. In our case there were 3000 calculations.

Fig. 8 shows the Gantt chart for all operations from the scheduling problem. On the vertical line are machines and time in hours is on the horizontal line. Each rectangle represents one operation. From the chart it can be seen that on machine 19 operations take a shorter time. This is the deoiling machine and it can operate with many parts concurrently. Machines M20 to M22 are galvanizing machines. Those machines operate also with big product batches. Makespan for the presented schedule is 452.98 hours, which can be seen in Fig. 8. Some machines do not operate at all. All alternative plans for each product were considered during the optimisation process and those machines were not chosen in any satisfactory scheduling plan. Machines from M1 to M18 are CNC machines. For these machines we also considered the working time at the beginning of the scheduling. If a machine is not available at the beginning the grey rectangle in Fig. 8 shows finished time of the production. And after that the product can be scheduled on this machine. We believe that the major problem in this example was scheduling on CNC machines because the operations are the longest. Machines from M19 to M30 represent the second operation, third operation, etc. These operations mostly take a short time and operate with big product batches.

The proposed genetic algorithm was tested on a similar problem from Gao et al. [23]. There are six jobs and five different machines, each job has several alternative plans. The results are in Table 4. Makespan is the result of the algorithm. Probability $p_{r}, p_{c}$ and $p_{m}$ are settings of probability for reproduction, crossover and mutation, respectively.

Computation time cannot be directly compared as it was not recognized as bottle-neck due to different programming environments. When the target functions (makespan) the results are close together. The proposed GA results in longer makespans, but it is good enough for practical application. The results from all cases of the proposed GA are almost the same. The increase of the population size in this simple problem does not yield significantly better results. The closest makespan is achieved in the second case. With a population size ten times smaller, almost the same result is obtained. We believe that the result in the second case is satisfactory for this simple problem.

After all these comparisons a specific solution for the production of turned parts' has been created: combined weighted function offers the satisfactory solution. From the point of view of the sales department, minimum delays are top priority, while on the other hand, for the production department and management, minimum costs are top priority. This target function allows both.

\section{CONCLUSION}

This article has shown how to apply a genetic algorithm for batch scheduling on an example of the production of turned parts,. Each criterion or target function appears to be very 
convincing, which could result in a dead end. For this reason, it is vital to check combinations of different target functions as in the case of combined weighted function. The proposed criterion for the production of turned parts includes total costs and delays. For the lowest common costs, additional delays will have to be accepted.

Table 4. Comparison of the results

\begin{tabular}{|c|c|c|c|c|}
\hline & $\begin{array}{c}\text { Gaos' } \\
\text { approach }\end{array}$ & \multicolumn{3}{|c|}{ Proposed GA } \\
\hline Code & $\mathrm{C}++$ & \multicolumn{3}{|c|}{ VB } \\
\hline \multirow{2}{*}{ Computer } & \multirow{2}{*}{$\begin{array}{c}2 \mathrm{Ghz} \\
\text { Core }{ }^{\mathrm{TM} 2} \\
\text { Duo CPU }\end{array}$} & \multicolumn{3}{|c|}{$\begin{array}{c}1.66 \mathrm{Ghz} \\
\text { Core }^{\mathrm{TM}} 2 \mathrm{CPU}\end{array}$} \\
\hline & & $\begin{array}{c}1^{\text {st }} \\
\text { case }\end{array}$ & $\begin{array}{c}2^{\text {rd }} \\
\text { case }\end{array}$ & $\begin{array}{c}3 \mathrm{rd} \\
\text { case }\end{array}$ \\
\hline Pop size & 200 & 200 & 20 & 60 \\
\hline Max gens & 50 & 50 & 50 & 50 \\
\hline Iterations & 20 & 20 & 20 & 20 \\
\hline$p_{r}$ & 0.1 & 0.1 & 0.1 & 0.2 \\
\hline$p_{c}$ & 0.8 & 0.8 & 0.8 & 0.9 \\
\hline$p_{m}$ & 0.1 & 0.1 & 0.1 & 0.01 \\
\hline Makespan & 92 & 96 & 95 & 96 \\
\hline
\end{tabular}

Finally, it was possible to compare the results from the selected target function and the initial plan, shown in Table 2. It was applied on the machine according to when the orders reached our company and for each job first an alternative plan was chosen. The costs of the combined weighted function drop by $69.1 \% .15 .6 \%$ amount to the total cost, while the rest is owing to the machines being chosen correctly. The makespan moves from 1257.58 to 452.98 hours. The amount of saving is the result of our strong emphasis on delays. For this reason a special weight has been developed.

In addition to planning and scheduling of manufacturing activities, the presented model also allows optimisation of manufacturing plans and machines. In this case the solution area is much larger due to the fact that all available machines are varied within each operation of the plan. It is possible to also take account of the machines that are not yet present in the existing plans or exist only in investment plans.

\section{ACKNOWLEDEGMENT}

The research is supported by the Ministry of Higher Education, Science and Technology under the project P-MR-08/88. Operation part financed by the European Union, European Social Fund.

\section{REFERENCES}

[1] Errington, J. (1997). Advanced Planning and Scheduling (APS): a powerful emerging technology. Next Generation I.T. in Manufacturing, no. 315, p. 3/1-3/6.

[2] Tasič, T., Buchmeister, B., Ačko, B. (2007). The development of advanced methods for scheduling production process. Strojniški vestnik - Journal of Mechanical Engineering, vol. 53, no. 12, p. 844-857.

[3] Alting, L., Zhang, H-C. (1989). Computer aided process planning: the state-of-the-art survey. International Journal of Production Research, vol. 27, no. 4, p. 553-585.

[4] Huang, S.H., Zhang, H-C., Smith, M.L. (1995). A progressive approach for the integration of process planning and scheduling. IIE Transactions, vol. 27, no. 4, p. 456-464.

[5] Tan, W., Khoshnevis, B. (2000). Integration of process planning and scheduling - a review. Journal of Intelligent Manufacturing, vol. 11, no. 1, p. 51-63.

[6] Kumar, M., Rajotia, S. (2003). Integration of scheduling with computer aided process planning. Journal of Materials Processing Technology, vol. 138, no. 1-3, p. 297-300.

[7] Larsen, N.E. (1993). Methods for integration of process planning and production planning. International Journal of Computer Integrated Manufacturing, vol. 6, no. 1-2, p. 152-162.

[8] Wang, L., Shen, W. (2003). DPP: An agent-based approach for distributed process planning. Journal of Intelligent Manufacturing, vol. 14, no. 5, p. 429-439.

[9] Zhang, H-C. (1993). IPPM - A prototype to integrate process planning and job shop scheduling functions. CIRP Annals Manufacturing Technology, vol. 42, no. 1, p. 513-518. 
[10] Gao, L., Shao, X., Li, X., Zhang C. (2009). Integration of process planning and scheduling - A modified genetic algorithmbased approach. Computers \& Operation Research, vol. 36, no. 6, p. 2082-2096.

[11] Usher, J.M., Fernandes, K.J. (1996). Dynamic process planning - the static phase. Journal of Materials Processing Technology, vol. 61, no. 1, p. 53-58.

[12] Kumar, M., Rajotia, S. (2006). Integration of process planning and scheduling in a job shop environment. International Journal of Advanced Manufacturing Technology, vol. 28, no. 1-2, p. 109-116.

[13] Jain, A., Jain, P.K., Singh, I.P. (2006). An Integrated scheme for process planning and scheduling in FMS. The International Journal of Advanced Manufacturing Technology, vol. 30, no. 11-12, p. 1111-1118.

[14] Haddadzade, M., Razfar, M.R., Farahnakian, M. (2009). Integrating process planning and scheduling for prismatic part regards to due date. World Academy of Science, Engineering and Technology, vol. 51, p. 6467.

[15] Starbek, M., Potočnik, P., Grum, J., Berlec, T. (2008). Predicting Order Lead Times. Strojniški vestnik - Journal of Mechanical Engineering, vol. 54, no. 5, p. 308-321.

[16] Kopač, J., Soković, M., Rosu, M., Doicin, C. (2005). Quality and cost in production management process. Strojniški vestnik Journal of Mechanical Engineering, vol. 54, no. 3, p. 207-218.

[17] Balič, J., Ficko, M., Brezočnik, M. (2005). A model for forming a flexible manufacturing system using genetic algorithms. Strojniški vestnik - Journal of Mechanical Engineering, vol. 51, no. 1, p. 28-40.

[18] Yan, H-S., Zhang, X-D. (2007). A case study on integrated production planning and scheduling in a three-stage manufacturing system. IEEE Transactions on automation science and engineering, vol. 4, no. 1, p. 8692.

[19] Park, B.J., Choi, H.R. (2006). A genetic algorithm for integration of process planning and scheduling in a job shop. AI2006: Advances in Artificial Intelligence, p. 647657.

[20] Kimms, A. (1999). A genetic algorithm for multi-level, multi-machine lot sizing and scheduling. Computers \& Operations Research, vol. 26, no. 8, p. 829-848.

[21] Zhang, X.-D., Yan, H.-S. (2005). Integrated optimization of production planning and scheduling for a kind of a job. The International Journal of Advanced Manufacturing Technology, vol. 26, no. 7-8, p. $876-886$.

[22] Lee, H., Kim, S.-S. (2001). Integration of process planning and scheduling using simulation based genetic algorithms. The International Journal of Advanced Manufacturing Technology, vol. 18, no. 8, p. 586-590.

[23] Li, X., Gao, L., Shao, X., Zhang, C., Wang, C. (2010). Mathematical modeling and evolutionary algorithm-based approach for integrated process planning and scheduling. Computers and Operations Research, vol. 37, no. 4, p. 656-667.

[24] Lestan, Z., Brezočnik, M., Buchmeister, B., Brezočnik, S., Balič, J. (2009). Solving the job-shop scheduling problem with simple genetic algorithm. International Journal of Simulation Modelling, vol. 8, no. 4, p. 197205.

[25] Cheng, R., Gen, M., Tsujimura, Y. (1996). A tutorial survey of job-shop scheduling problems using genetic algorithms - I: representation. Computers and Industrial Engineering, vol. 30, no. 4, p. 983-997. 